\title{
The Influence of Optic and Polarographic Dissolved Oxygen Sensors Estimating the Volumetric Oxygen Mass Transfer Coefficient $\left(\mathrm{K}_{\mathrm{L}} \mathrm{a}\right)$
}

\author{
Gustavo Andres Baquero Rodriguez ${ }^{1} \&$ Jaime A. Lara-Borrero ${ }^{1}$ \\ ${ }^{1}$ Ciencia e Ingeniería del Agua y el Ambiente, Department of Civil Engineering, Pontificia Universidad \\ Javeriana, Bogotá, Colombia \\ Correspondence: Gustavo Andres Baquero Rodriguez, Department of Civil Engineering, Pontificia Universidad \\ Javeriana, Carrera 7 No 40-62, Bogotá Colombia. Tel: 571-320-8320. E-mail: baquerog@javeriana.edu.co
}

Received: January 16, 2016

Accepted: March 22, 2016

Online Published: June 15, 2016

doi:10.5539/mas.v10n8p142

URL: http://dx.doi.org/10.5539/mas.v10n8p142

The research is financed by Pontificia Universidad Javeriana, Bogotá, Colombia.

\begin{abstract}
Aeration is usually the most energy intensive part of the wastewater treatment process. Optimizing the aeration system is essential for reducing energy costs. Field tests oriented to estimate parameters related to oxygen transfer are a common approach to compare aeration systems. The aim of this research is to assess the effect of dissolved oxygen probe lag on oxygen transfer parameter estimation. Experimental procedures regarding to process automation and control were applied to quantify dissolved oxygen probe lag. We have measured oxygen transfer in clean water, under a wide range of conditions (airflow rate, diffuser characteristics and diffuser density), with optic and polarographic sensors for dissolved oxygen measurement. The oxygen transfer was measured as per ASCE Standard procedures. Nonparametric statistical tests were used to compare the estimated volumetric mass transfer coefficient $\mathrm{K}_{\mathrm{L}}$ a with different sensors. According to the results, there is not significant influence of the probe lag (also known as time constant) or probe characteristics on the parameters used to assess oxygen transfer efficiency. This fact has great relevance in common practice of aerobic process for wastewater treatment because dissolved oxygen monitoring is used as an input for decision making related to the energy optimization in the aeration system. Findings from these tests contradict previous studies which claim that lag time in polarographic sensors for the dissolved oxygen measurement can bias estimate $\mathrm{K}_{\mathrm{L}} \mathrm{a}$.
\end{abstract}

Keywords: oxygen transfer, dissolved oxygen, aeration efficiency, probe lag

\section{Introduction}

In activated sludge process, the energy consumed by the electromechanical equipment used for aeration typically demands more than $50 \%$ of the process power (DWA, 1996; Metcalf \& Eddy, 2013; Stenstrom \& Gilbert, 1981; US EPA, 1989).

Factors to be considered when studying oxygen transfer in fine-pore aeration systems covers a wide range: diffuser-related issues(Groves, Daigger, Simpkin, Redmon \& Ewing, 1992; Mueller, Boyle \& Popel, 2002; Diego Rosso \& Shaw, 2015), aerobic reactor characteristics(Eckenfelder, 1959; Mueller et al., 2002; Pittoors, Guo \& Van Hulle, 2014; Schierholz, Gulliver, Wilhelms \& Henneman, 2006) and operating conditions(Henkel, 2010; D Rosso, Iranpour \& Stenstrom, 2005).

Equation 1 presents the basic model for oxygen transfer in a disperse gas-liquid system. This equation relates the oxygen transfer rate (OTR) with the volumetric liquid-phase oxygen transfer coefficient $\left(\mathrm{k}_{\mathrm{L}} \mathrm{a}\right)$. The driving force for oxygen transfer being the concentration gradient between the dissolved oxygen (DO) and the saturation $\left(\mathrm{DO}^{\text {sat }}\right)$.

$$
\text { OTR }=k_{L} \mathrm{a}\left(\mathrm{DO}^{\text {sat }}-\mathrm{DO}\right) \mathrm{V}
$$

Where: OTR: oxygen transfer rate (mass $\mathrm{O}_{2}$, length ${ }^{-3}$, time ${ }^{-1}$ ), $\mathrm{k}_{\mathrm{L}} \mathrm{a}$ : liquid-side volumetric oxygen transfer coefficient $\left(\right.$ time $\left.^{-1}\right)$, $\mathrm{DO}^{\text {sat }}$ : dissolved oxygen concentration at saturation (mass $\mathrm{O}_{2}$, length ${ }^{-3}$ ), DO: dissolved oxygen concentration (mass $\mathrm{O}_{2}$, length ${ }^{-3}$ ).

From there, we move to the basic model of oxygen transfer as volumetric coefficient. As far as the resulting 
coefficient is concerned, " $\mathrm{k}_{\mathrm{L}}$ " corresponds to the velocity of gas-liquid oxygen transfer and "a" to the bubbles specific area (i.e., surface area per unit volume). Since the measurement of interfacial areas often turns out to be impractical, the coefficient $\mathrm{k}_{\mathrm{L}}$ a becomes a reference variable for characterizing aeration (Eckenfelder, 1959).

Determining $\mathrm{K}_{\mathrm{L}} \mathrm{a}$ in an aerobic reactor is essential to establish its aeration efficiency. Usually, measurement of oxygen transfer from diffused gas and mechanicaloxygenation devices to clean water is done according to the ASCE/EWRI Standard 2006-2 (American Society of Civil Engineers, 2007).

Measuring dissolved oxygen in wastewater treatment process is considered of interest as input for the control of dissolved oxygen concentrations inside the aerobic reactor and consequently the process energy demand. Currently, the most common method for dissolved oxygen measurements is using a dissolved oxygen sensor (usually comprised of a controller, cable, probe and a sensing element). According to their measure principle, there are commercially available electrochemical and optical sensors. Electrochemical sensors can be sub-divided into polarographic and galvanic sensors. Optical measurement methods can be sub-divided into Intensity-based and lifetime-based optical sensors (Bogue, 2008; Lee \& Tsao, 1979; YSI Incorporated, 2009).

Philichi and Stenstrom (1989) outline a procedure for establishing the response time of a sensor and its effect on estimating $\mathrm{K}_{\mathrm{L}}$ a. The typical response time of polarographic sensors with highly sensitive membranes is approximately $8 \mathrm{~s}$, and for optic sensors, the response time approaches $40 \mathrm{~s}$ (YSI Incorporated, 2009).

Development of standard procedures for oxygen transfer parameter estimation began in the 1980s (Brenner, 1983). At that time technology for optic dissolved oxygen probes was not commercially available. The first references to applications of optic dissolved oxygen probes in wastewater treatment are from the year 2000 (Santos \& Farahi, 2014). The recent development of this technology and the fact that is widely commercially available is a good reason to consider using them in oxygen transfer parameter estimation tests. According to the literature review made, the effects of measuring response time on the optical sensors when they are applied in estimating the $\mathrm{K}_{\mathrm{L}}$ a has not been considered yet.

According to manufacturers, each type of dissolved oxygen sensors (optic and polarographic) has advantages and disadvantages. From a wastewater treatment plant operator point of view, optical sensors present advantages in terms of lower maintenance than polarographic sensors. In practical terms, lower maintenance appears as an attractive alternative when selecting dissolved oxygen sensors. More details regarding thesensors specifications are widely available indissolved oxygen sensors manufacturer's website.

\section{Method}

A single bench test has been used throughout the whole experimentation. Two main research stages have been conducted: i) Measure dissolved oxygen probe lag, ii) Measure oxygen transfer in clean water. This section provides details on experimental methods as well as details for each one of the stages of the research:

\subsection{Experimental Set-up}

The experimental setup used to measure oxygen transfer in the clean water consists of a 2000 liters High Density Polyethylene (HDPE) tank, galvanized steel pipeline for air supply, one or two fine bubble diffusers, air flow measurement and regulation devices. Dissolved oxygen probes were installed hanging over the top of the tank, exactly in the same position during the tests. Useful depth of the tank is 1.5 meters. An illustration of the main components of the experimental setup is shown in Figure 1.

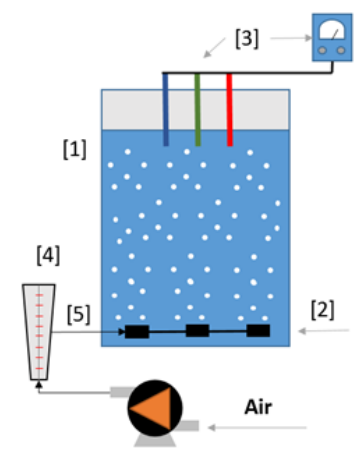

Figure 1. Illustration of the major components of experimental setup used in the measurement of oxygen transfer in the clean water

[1] Tank filled with 2000 Liters of tap water. [2] Fine-bubble diffuser. [3] Dissolved oxygen and total dissolved 
solids probes. [4] Air flow meter Dwyer RMB-55-SSV flowmeter (Range 40-400 SCFH). [5] Manometer Merrill PGP100 (Range 0-100 PSI).

Similarity with commonly used wastewater components was a priority in the design phase of the bench test. This is the main reason because diffusers typically used in the industry were selected. Three different fine bubble diffusers were used in the experimentation. Diffusers were selected looking for different shapes and materials. Table 1 presents their characteristics.

Table 1. Characteristics of the diffusers

\begin{tabular}{|c|c|c|c|c|c|c|c|}
\hline \multirow{2}{*}{ Diffuser ID } & \multirow{2}{*}{ Brand } & \multirow{2}{*}{ Shape } & \multirow{2}{*}{ Size } & \multirow{2}{*}{ Model } & \multirow{2}{*}{ Material } & Range & \multirow{2}{*}{$\begin{array}{l}\text { Conditions } \\
\text { Evaluated } \mathrm{m} 3 / \mathrm{h}\end{array}$} \\
\hline & & & & & & $\mathrm{m} 3 / \mathrm{h} * *$ & \\
\hline \multirow{2}{*}{1} & \multirow{2}{*}{ OTT } & \multirow{2}{*}{ Tubular } & \multirow{2}{*}{$2.44 "$ x 24" } & \multirow{2}{*}{ Flexair } & \multirow{2}{*}{ Silicon } & \multirow{2}{*}{$2.0-8.0$} & 1 diffuser -1 to 7 \\
\hline & & & & & & & 2 diffusers -1 to 7 \\
\hline 2 & Sanitaire & Disc & 9" & Silver Series II & EPDM* & $1.0-6.5$ & 1 diffuser -1 to 6 \\
\hline 3 & SSI & Disc & $12 "$ & AFD350 & EPDM* $^{*}$ & $4.2-8.3$ & $\begin{array}{l}1 \text { diffuser }-1 \text { to } 8 \\
2 \text { diffusers }-2 \text { to } 10\end{array}$ \\
\hline
\end{tabular}

* Ethylene propylene diene monomer (M-class). ** Consistent with the manufacturer guidelines.

\subsubsection{Measuring Instruments Used}

Eight dissolved oxygen probes were used in experimentation. Table 2 presents the characteristics of each one of the dissolved oxygen probes. High sensitivity membranes were installed in all of the YSI polarographic probes (YSI 5776 and YSI 5908). For measuring the total dissolved solids a YSI EC300 conductivity meter was used.

Table 2. Dissolved oxygen probes used in the tests

\begin{tabular}{llll}
\hline Sensor ID & Brand & Model & Electrode \\
\hline 1 & YSI & 58 & Polarographic \\
2 & YSI & 200 & Polarographic \\
3 & YSI & DO Pro & Optic \\
4 & YSI & 58 & Polarographic \\
5 & YSI & 505 & Polarographic \\
6 & EXTECH & DO 700 & Polarographic \\
7 & WTW & FDO 700 IQ & Optic \\
8 & YSI & 50 & Polarographic \\
\hline
\end{tabular}

Sensors were checked and calibrated each of the days in which experimentation was done. As a precaution, we review and replaced batteries on a regular basis and membranes of dissolved oxygen probes when it was needed. These procedures follow directions as recommended by the manufacturer.

\subsection{Dissolved Oxygen Probe Lag}

\subsubsection{Methodology}

The objective of this experimental procedure is to collect the data of a nearly instantaneous change in dissolved oxygen concentration. In this particular application, the sudden change in dissolved oxygen concentration is equivalent to a unit step. These tests are developed taking dissolved oxygen sensors from water with a low dissolved oxygen concentration (O.D. $\approx 0 \mathrm{mg} / \mathrm{L}$ ) rapidly to water with dissolved oxygen at saturation concentration (O.D. $\approx 7.0 \mathrm{mg} / \mathrm{L}$ ). In this case, the water volume out of dissolved oxygen was in an 8 liters beaker. 
The water containing dissolved oxygen concentration saturation was inside the tank of 2000 liters mentioned before. With each one of the dissolved oxygen probes used three replicates of the experiments were performed. Data analysis is brought forward from the average of collected data. Recorded time and dissolved oxygen data regarding probe to respond to the change is used as a basis to estimate the probe lag.

Oxygen removal is done by consuming the dissolved oxygen using sodium sulfate $\left(\mathrm{Na}_{2} \mathrm{SO}_{3}\right)$ analytical grade with cobalt chloride $\left(\mathrm{CoCl}_{2}\right)$ analytical grade added as a catalyst. The amount of each chemical is estimated according to guidelines of the standard ASCE/EWRI Standard 2006-2.

According to Smith and Corripio (1997) the term "Time Constant" is referred to the specific vocabulary of process control. As reported by Philichi and Stenstrom (1989), the term "Probe Lag" is referred to the specific vocabulary of wastewater treatment. However, these two expressions have the same meaning because they represent the same characteristic of the sensor. It is important to notice that for this work the term Probe Lag is used.

\subsubsection{Data Processing}

A model commonly used in the description of process dynamics is the so-called "First order plus dead-time" (FOPDT). In process automation and control the FOPDT model is used when system's response to a step input is being estimated. Said response is the process reaction curve (Smith \& Corripio, 1997). The procedure to estimate the probe lag use as reference a high exchange rate region of the process, according to the dissolved oxygen data collected.

Data were processed using two similar procedures. The one described by Philichi and Stenstrom (1989) is a procedure previously applied to dissolved oxygen probes. The procedure described by Smith and Corripio (1997), dubbed "Fit 3" is a general procedure applied to process automation and control, however, this mathematical procedures used to assess the response to a unit step are used to quantify dissolved oxygen probe lag.

Smith and Corripio (1997) present different procedures applicable to estimate the probe lag. The so-called "Fit 1 " is similar to that found in Philichi and Stenstrom (1989). From the review presented by Smith and Corripio (1997), they recommend the use of the procedure dubbed "Fit 3" as a more precise one. This is the reason to have in consideration two procedures in this work.

Threeparameters are used to describe the FOPDT: (i) Time constant $(\tau)$ : After one time constant the response reaches $63.2 \%$ of its final change, and in five "time constants" it reaches over $99 \%$ of the change. (ii) Total change ( $\triangle \mathrm{Cs}$ ): Regarding dissolved oxygen concentration once system reach steady state conditions. (iii) Dead time $\left(\mathrm{t}_{0}\right)$ : Time delays are caused by probe lag (Smith \& Corripio, 1997).

\subsection{Measure Oxygen Transfer in Clean Water}

\subsubsection{Methodology}

The oxygen transfer has been measured as per ASCE Standard procedures "Measurement of Oxygen Transfer in Clean Water" ASCE/EWRI Standard 2006-2 (American Society of Civil Engineers, 2007).

For aeration parameter determination, the dissolved oxygen on the water is decreased to a low value (O.D. $\approx 0$ $\mathrm{mg} / \mathrm{L}$ ), aeration is then started at a constant air flow rate and the increase in dissolved oxygen is monitored using a dissolved oxygen probe. Once the dissolved oxygen reach a steady state (Saturated dissolved oxygen concentration), data collection is complete. In order to remove oxygen from the water, Sodium Sulfite $\left(\mathrm{Na}_{2} \mathrm{SO}_{3}\right)$ analytical grade and Cobalt Chloride $\left(\mathrm{CoCl}_{2}\right)$ analytical grade were used.

During the experimentation phase, tests were made with three (3) different models of diffusers, operating the aeration system in different airflows (from 1 to $8 \mathrm{~m}^{3} / \mathrm{h}$ according to the range recommended by the manufacturer), for each tested scenario, two (2) repetitions were made. The dissolved oxygen concentrations were measured with dissolved oxygen probes described in Table 2.

These tests were aimed to determine the effect of using optical dissolved oxygen probes, airflow rate, diffuser type and diffuser density in the parameters estimation associated with the oxygen transfer efficiency in clean water.

\subsubsection{Data Processing}

The data processing to estimate $\mathrm{K}_{\mathrm{L}} \mathrm{a}$ is described in ASCE/EWRI Standard 2006-2 (American Society of Civil Engineers, 2007). A parameter estimation tool dubbed DOPar (Version 3-0-3) is available for ease of processing data collected in oxygen transfer tests (Kartiki S. Naik, 2012). This tool performs a non-steady state analysis of re-aeration data under the required procedures of the ASCE/EWRI Standard 2006-2. A description of the 
optimization technique used to fit the parameters is provided in Stenstrom, Hwang, et al., (1981). For the estimation of the aeration parameters DOPar (Version 3-0-3) consider information regarding test conditionsas the atmospheric pressure, temperature, total dissolved solids (TDS), initial dissolved oxygen and saturation, as well as the dissolved oxygen concentrations recorded during the test.

The ASCE/EWRI Standard 2006-2 anticipates that initial collected data has to be truncated by the $20 \%$. Consequently, the present work has adopted as reference $1 \mathrm{mg} / \mathrm{L}$ to eliminate the data below this concentration. Based on experience during the data processing, the author can confirm that following the recommendation eliminates interference in the $\mathrm{K}_{\mathrm{L}}$ a estimation when there is time-out in the collected data.

During the test, a camera was used to record the screen of the dissolved oxygen probe controllers. Once the tests were completed, by typing values, the recorded videos were employed to build up a database containing elapsed time, dissolved oxygen concentration and water temperature.

\subsection{Statistical Tests Employed}

R programming language (R Core Team, 2015) was used to the statistical analysis. Nonparametric test were applied to the data such as Kruskal-Wallis Rank Sum Test and Wilcoxon Rank-Sum Test.

The Kruskal-Wallis test is used to test the null hypothesis $\mathrm{H}_{0}$ that $k$ independent samples are from identical populations. The test is a nonparametric procedure for testing the equality of means in the one-factor analysis of variance when the experimenter wishes to avoid the assumption that the samples were selected from normal populations (Walpole, Myers, Myers, \& Ye, 2011)

The Wilcoxon Rank-Sum test is used to determine whether the median difference between paired observations equals zero, under this condition, we can test the null hypothesis $\mu=\mu_{0}$. In this test we note the magnitudes and the signs of the paired differences from two samples of observations and then rank the absolute values of the differences (Kottegoda \& Rosso, 2008; Walpole et al., 2011).

\section{Results and Discussion}

\subsection{Dissolved Oxygen Probe Lag}

The details of the results obtained for each dissolved oxygen probe are summarized in Table 3 . These results show that polarographic sensors have probe lags below 10 seconds, for this group of probes the variation of the estimated probe lag is low. On the other hand, optic dissolved oxygen probes have 10 to 20 times higher response time than polarographic probes. Under the same operation conditions polarographic dissolved oxygen probes have a lower response times than optic ones, the findings regarding probe lag for optic and polarographic dissolved oxygen probes are consistent to literature (Santos \& Farahi, 2014; YSI Incorporated, 2009). Measurement technology in dissolved oxygen probes is directly linked to the probe lag.

Regarding the methodology utilized for the probe lag estimation, the results obtained do not show significant differences and the orders of magnitude are similar. Despite the fact that Smith and Corripio (1997) recommend the methodology called "Fit 3" over the "Fit 1" the results obtained showed that the methodology suggested by Philichi and Stenstrom (1989) is applicable.

Table 3. Probe Lag (time constant) estimated for the dissolved oxygen probes

\begin{tabular}{llll}
\hline \multirow{2}{*}{ Description } & Sensor & Probe Lag “ $\tau$ ” (seconds) & \\
\cline { 2 - 4 } & No & Philichi, Stenstrom (1989) & "Fit 3" Smith \&Corripio(1997) \\
\hline $\mathrm{P}$ & 1 & 4.10 & $*$ \\
$\mathrm{P}$ & 2 & 7.65 & 6.80 \\
$\mathrm{O}$ & 3 & 136.99 & 213.66 \\
$\mathrm{P}$ & 4 & 3.80 & 1.74 \\
$\mathrm{P}$ & 5 & 7.50 & 3.76 \\
$\mathrm{P}$ & 6 & 6.97 & 3.21 \\
$\mathrm{O}$ & 7 & 95.24 & 93.56 \\
$\mathrm{P}$ & 8 & 6.92 & 4.41 \\
\hline
\end{tabular}

* Not measured value 


\subsection{Measurement Oxygen Transfer in Clean Water}

The results presented in Figure 2[A] to Figure 2[D] show how air flow rate is related with the $\mathrm{K}_{\mathrm{L}}$ a estimated values using each type of dissolved oxygen probes (optic and polarographic) as well as different diffuser density

\subsubsection{Impact of the Probe Technology on $\mathrm{K}_{\mathrm{L}}$ a Estimation.}

The results of the oxygen transfer tests are shown in the Figure 2. The results show no difference between $\mathrm{K}_{\mathrm{L}} \mathrm{a}$ values estimated from optic or polarographic dissolved oxygen probes. According to results obtained, $\mathrm{K}_{\mathrm{L}} \mathrm{a}$ will increase parallel to the airflow rate. Differences between diffusers performance, considering one and two diffusers, are evident when comparing the $\mathrm{K}_{\mathrm{L}} \mathrm{a}$ order of magnitude in each air flow rate.

The statistical tests (Kruskal-Wallis test) confirms that probe or the probe technology (optic or polarographic) does influence the results of the estimated $\mathrm{K}_{\mathrm{L}} \mathrm{a}$ ( $\mathrm{p}$-value $>0.05$ in all cases). The absence of influence exercised by the sensor or the sensor technology (optic or polarographic) on $\mathrm{K}_{\mathrm{L}} \mathrm{a}$ estimation can be confirmed by the Wilcoxon signed-rank test (p-value $>0.05$ in all cases). That is to say, this test did not establish significant differences for estimated $\mathrm{K}_{\mathrm{L}} \mathrm{a}$ based on the probe or the probe technology (optic or polarographic).

Findings from these tests contradict previous studies which claim that lag time in polarographic dissolved oxygen probes response can bias estimates of $\mathrm{K}_{\mathrm{L}} \mathrm{a}$ (Philichi \& Stenstrom, 1989). As a general guideline, according to the ASCE/EWRI Standard 2006-2 the probe lag should be less than $0.02 / \mathrm{K}_{\mathrm{L}}$ a (American Society of Civil Engineers, 2007). To verify the probe response time against the guideline given in the ASCE/EWRI Standard 2006-2 an optic probe lag data was used as reference to compared with the standard: $\mathrm{K}_{\mathrm{L}}$ a value $=8 \mathrm{~h}^{-1}$ and a probe lag $\sim 200 \mathrm{~s}$ or its equivalent $0,0556 \mathrm{~h}$ (see Table 3). According to the ASCE/EWRI Standard 2006-2, the reference was $0.0025 \mathrm{~h}$ for the probe response time (Estimated from $0.02 / 8 \mathrm{~h}^{-1}$ ). When comparing the reference value $(0.0025 \mathrm{~h})$ to the optic probe lag data $(0.0556 \mathrm{~h})$ it makes it clear that the optic probe lag used in this work is higher than the reference value and do not meet the standard guidelines. Nevertheless, according to the results there is no statistical difference between $\mathrm{K}_{\mathrm{L}} \mathrm{a}$ values estimated from optic or polarographic dissolved oxygen probes.

The results reported by Philichi and Stenstrom (1989) were determined from an experiment conducted with dissolved oxygen probes with probe lags between 5.0 and 7.0 seconds. In the present investigation, the assessment has been based on dissolved oxygen probe lags between 3.8 y 200 seconds, including optical sensors. These results arise from experimentation in values of $\mathrm{K}_{\mathrm{L}}$ a between 1.7 and $25 \mathrm{~h}^{-1}$, using diffusers with the characteristics of the ones used in wastewater treatment practice. Tested air flowrates are consistent with the manufacturer guidelines, in consequence, they are applicable to the typical operational conditions of wastewater industry.

The authors consider that this is a starting point to develop a detailed review of the ASCE/EWRI Standard 2006-2 guidelines as well as the use of widely accepted technologies such as optic dissolved oxygen probes for the measuring of oxygen transfer in clean water.

Our work leads to the conclusion that the type of sensor used in the oxygen transfer tests don't have significant variations on the estimated $\mathrm{K}_{\mathrm{L}} \mathrm{a}$, in any case, when a dead time is recorded in the beginning of the test, it is necessary to apply data truncation procedure in accordance with the recommendations given in the ASCE/EWRI Standard 2006-2 (American Society of Civil Engineers, 2007).

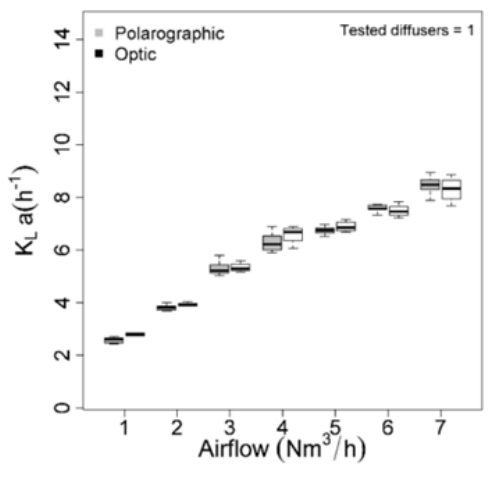

$[\mathrm{A}]$

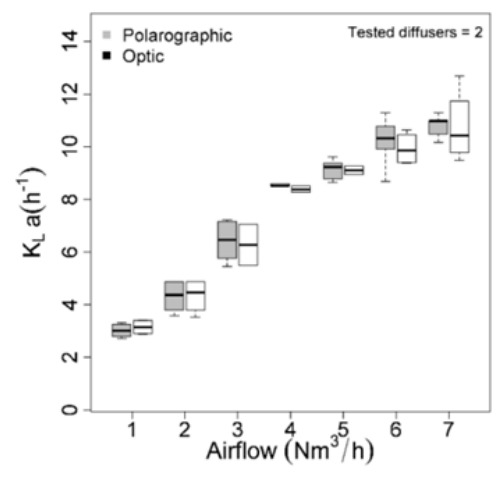




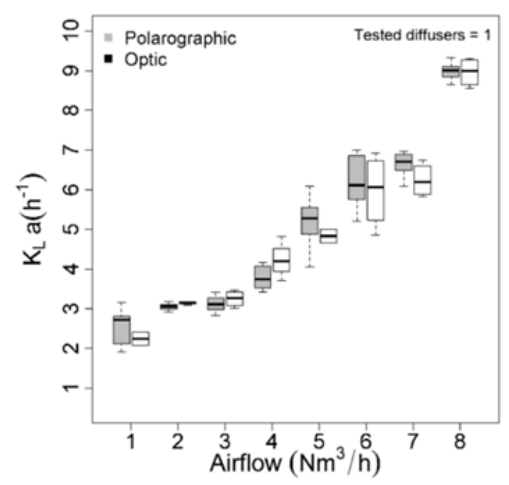

$[\mathrm{C}]$
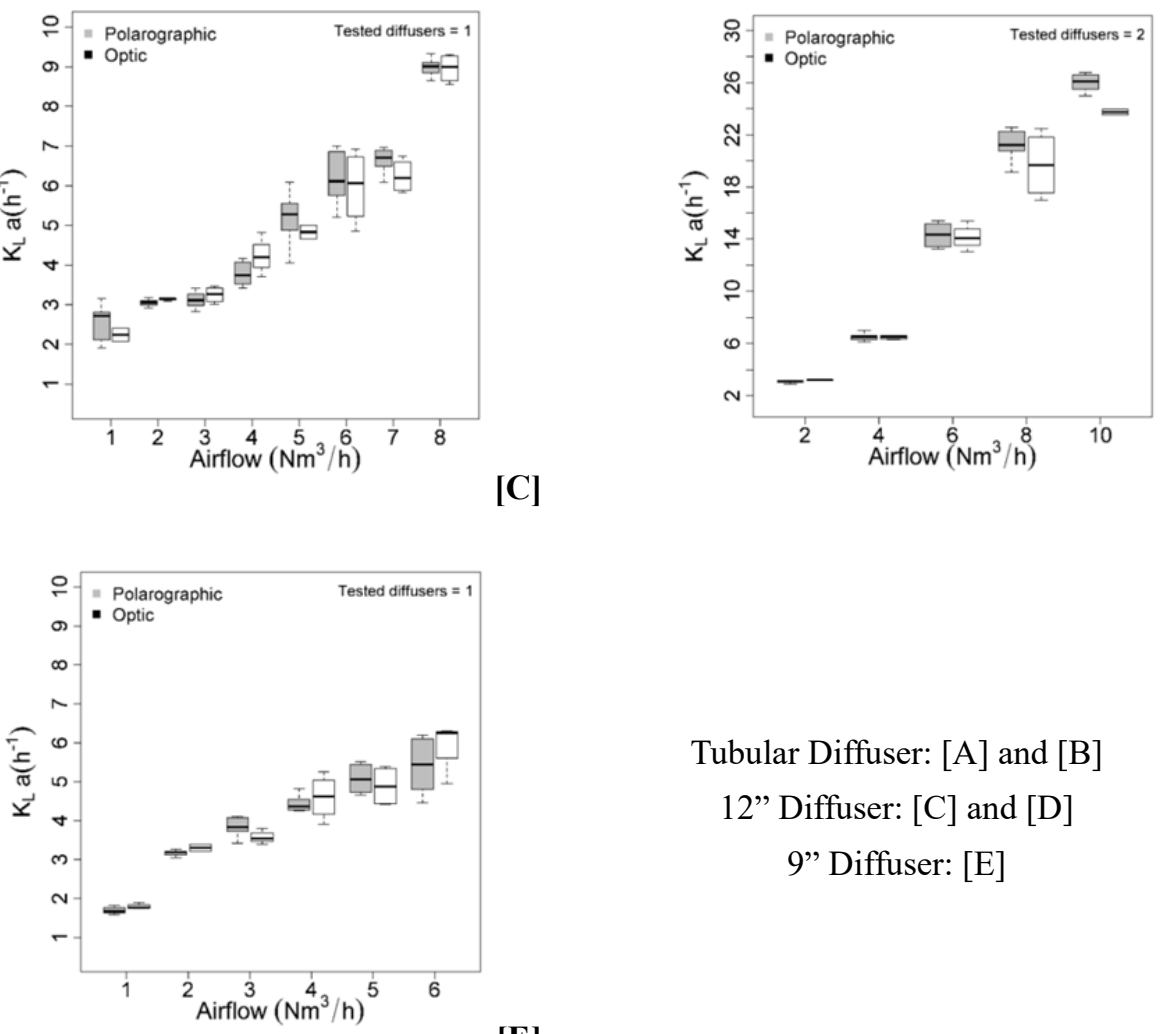

$[\mathbf{E}]$

Tubular Diffuser: $[\mathrm{A}]$ and $[\mathrm{B}]$

12" Diffuser: $[\mathrm{C}]$ and $[\mathrm{D}]$

9" Diffuser: [E]

Figure 2. Results of the tests at different air flow rates

\subsubsection{Impact of Air Flow Rate on $\mathrm{K}_{\mathrm{L}} \mathrm{a}$}

Regarding to the oxygen transfer as a function of the air flow rate, the tendency of the findings of this research, is consistent with the reported by several authors. In aeration systems the oxygen transfer efficiency is a function of the air flow rate and both keep a direct relationship (Gillot, Capela-Marsal, Roustan, \& Héduit, 2005; Jenkins, 2013; Liu, Li, \& Zhang, 2011; Mueller et al., 2002; D Rosso et al., 2005). High water flow regimens, associated with high air flow rates, has as consequence the increase in internal bubble recirculation of gas and high surface renewal rates (interface gas - liquid) (D. Rosso, Huo, \& Stenstrom, 2006).

However, despite the tendency, the numeric results cannot be compared with already reported values. The foregoing, because factors such as tank shape, water column depth/height and the diffusers density or the diffuser type are factors affecting oxygen transfer efficiency. Characteristics of the bench test didn't match characteristics of other previously reported.

Statistical tests (Kruskal-Wallis test) have shown significance evidence that airflow rate and diffuser characteristics affect the variability of the $\mathrm{K}_{\mathrm{L}} \mathrm{a}$, test revealed that $93.4 \%$ of the variability of $\mathrm{K}_{\mathrm{L}} \mathrm{a}$ was related to the airflow rate. The Wilcoxon Signed Rank test confirms this fact, air flow rate has a significant difference in the $\mathrm{K}_{\mathrm{L}}$ a value estimated in the tests ( $\mathrm{p}$-value $<0.05$ in all cases).

\subsubsection{Impact of Diffuser Density on $\mathrm{K}_{\mathrm{L}} \mathrm{a}$}

Regarding the effect of diffuser density on oxygen transfer efficiency, when comparing $\mathrm{K}_{\mathrm{L}} \mathrm{a}$ results from test with 1 and 2 diffusers for the same air flow rate (Figure 2[A] to Figure 2[D]), statistical tests (Kruskal-Wallis test) have shown significance evidence that diffuser density affect the $\mathrm{K}_{\mathrm{L}} \mathrm{a}$. For the tubular diffuser $83 \%$ of the variability of $\mathrm{K}_{\mathrm{L}}$ a was related to the diffuser density, in the case of the 12" diffusers, for airflow rates above 4 $\mathrm{Nm}^{3} / \mathrm{h}, 86 \%$ of the variability is related to the diffuser density. The Wilcoxon Signed Rank test confirms this fact, the diffuser density used in the test is related to statistically significant differences in the $\mathrm{K}_{\mathrm{L}} \mathrm{a}$ (p-value $>0.05$ in all cases). The results obtained show a clear influence of the diffuser density on the oxygen transfer efficiency, higher the diffuser density higher the $\mathrm{K}_{\mathrm{L}} \mathrm{a}$. This means that estimated value for $\mathrm{K}_{\mathrm{L}} \mathrm{a}$ is affected by the diffuser density (Airflow from 2 to $10 \mathrm{Nm}^{3} / \mathrm{h}, \mathrm{K}_{\mathrm{L}}$ a from $\sim 4$ to $\sim 26 \mathrm{~h}^{-1}$ ). 
The results and the analysis are consistent with other investigations that have shown similar results, an increase in diffuser density results in an increase in oxygen transfer efficiency. A common application of this fact on plug flow reactors is tapered aeration, a higher diffuser density is installed at the influent end of the tank than the effluent end. This optimizes oxygen transfer, since the oxygen uptake rate is higher at the influent end of the basin (Jenkins, 2013; Mueller et al., 2002; US EPA, 1989). As bubble size is a critical parameter in diffused bubble systems because it determines the interfacial surface area and bubble-rise velocity, increasing the diffuser density for the same air flow rate, lower initial bubble size and interaction between bubbles after the formation.

\subsubsection{Effective Diffuser Area and Oxygen Transfer Performance}

On a side note, according to the results (See Table 4), considering $\mathrm{K}_{\mathrm{L}} \mathrm{a}$ in relation to the effective diffuser area $\left[\mathrm{K}_{\mathrm{L}} \mathrm{a}\left(\mathrm{h}^{-1}\right) /\right.$ diffuser area $\left.\left(\mathrm{m}^{2}\right)\right]$, the 9" diffuser have been proven to be twice as effective as the tubular diffuser (single diffuser tests). This topic is not the main subject of this research, even though, proves to be an interesting point of view when a diffuser selection process have to be carried out.

Table 4. Ratio between Airflow Rate and Diffuser Area

\begin{tabular}{llll}
\hline $\begin{array}{l}\text { Airflow Rate } \\
\mathrm{m}^{3} / \mathrm{h}\end{array}$ & $\begin{array}{l}\text { Tubular Diffuser } \\
\mathrm{K}_{\mathrm{L}} \mathrm{a}\left(\mathrm{h}^{-1}\right) / \mathrm{m}^{2}\end{array}$ & $\begin{array}{l}\text { 9" Diffuser } \\
\mathrm{K}_{\mathrm{L}} \mathrm{a}\left(\mathrm{h}^{-1}\right) / \mathrm{m}^{2}\end{array}$ & $\begin{array}{l}12 \text { " Diffuser } \\
\mathrm{K}_{\mathrm{L}} \mathrm{a}\left(\mathrm{h}^{-1}\right) / \mathrm{m}^{2}\end{array}$ \\
\hline 1 & 24.1 & 49.8 & 36.8 \\
2 & 35.1 & 91.6 & 45.6 \\
3 & 48.8 & 108.3 & 46.7 \\
4 & 58.7 & 127.0 & 57.9 \\
5 & 62.7 & 144.9 & 86.2 \\
6 & 69.7 & 158.7 & 91.3 \\
7 & 77.9 & & 97.1 \\
8 & & & 132.5 \\
\hline
\end{tabular}

Since the aeration efficiency is directly related to the costs of the energy needed for the operation of an aeration system it is relevant to highlight the importance of correct selection of diffusers to be installed in activated sludge process for wastewater treatment.

\subsection{Importance of the Findings}

On the basis of the results obtained for the $\mathrm{K}_{\mathrm{L}}$ a estimated using different types of dissolved oxygen probes (optic and polarographic) we can conclude that there is no significant influence of the probe lag (time constant) or probe characteristics on the parameters used to assess oxygen transfer efficiency in clean water. This means that $\mathrm{K}_{\mathrm{L}}$ a typical values of fine-bubble diffusers in clean water $\left(\sim 1.5\right.$ to $\left.\sim 26 \mathrm{~h}^{-1}\right)$ are not affected by the dissolved oxygen probe characteristics (optic or polarographic) or by their probe lag $(\tau<200 \mathrm{~s})$.

Under the conditions tested in this research air flow rate and diffuser density are the most contributing factors related to $\mathrm{K}_{\mathrm{L}}$ a estimation. According to the results, we confirm that air flow rate, diffuser characteristics and diffuser density has a direct influence on the performance of the oxygen transfer process (Measured as $\mathrm{K}_{\mathrm{L}} \mathrm{a}$ ).

To prevent data processing errors it is importantto avoid dead time effect, it is necessary to apply data truncation procedure when a dead time is recorded in the beginning of the test.

\section{Acknowledgments}

This study was funded by the Pontificia Universidad Javeriana as part of Project 6571. Additionally, COLCIENCIAS (Colombian Administrative Department of Science, Technology and Innovation) has provided financial support for the Doctoral Studies of the corresponding author.

\section{References}

American Society of Civil Engineers. (2007). Measurement of oxygen transfer in clean water ASCE standard, $A S C E / E W R I$ 2-06. Reston, VA: American Society of Civil Engineers. http://dx.doi.org/10.1061/9780784408483

Bogue, R. (2008). Environmental sensing: strategies, technologies and applications. Sensor Review, 28(4), 275-282. http://dx.doi.org /10.1108/02602280810902550

Brenner, R. C. (1983). Development of standard procedures for evaluating oxygen transfer devices (Vol. EPA 600/2-83-102). U.S. EPA. 
DWA. (1996). ATV-M 209E. Measurement of the Oxygen Transfer in Activated Sludge Aeration Tanks with Clean Water and in Mixed Liquor (1st Ed.). DWA.

Eckenfelder, W. W. (1959). Factors Affecting the Aeration Efficiency of Sewage and Industrial Wastes. Sewage and Industrial Wastes, 31(1), 60-70.

Gillot, S., Capela-Marsal, S., Roustan, M., \& Héduit, A. (2005). Predicting oxygen transfer of fine bubble diffused aeration systems - model issued from dimensional analysis. Water Research, 39(7), 1379-1387. http:// dx.doi.org /10.1016/j.watres.2005.01.008

Groves, K. P., Daigger, G. T., Simpkin, T. J., Redmon, D. T., \& Ewing, L. (1992). Evaluation of oxygen transfer efficiency and alpha-factor on a variety of diffused aeration systems. Water Environment Research, 64(5), 691-698. http:// dx.doi.org /10.2175/WER.64.5.5

Henkel, J. (2010, July 26). Oxygen Transfer Phenomena in Activated Sludge. TU Darmstadt, Darmstadt. Retrieved from http://tuprints.ulb.tu-darmstadt.de/id/eprint/3008

Jenkins, T. E. (2013). Aeration control system design: a practical guide to energy and process optimization (1st Ed.). Hoboken, New Jersey: John Wiley and Sons, Inc. http://dx.doi.org/10.1002/9781118777732

Kartiki S. Naik, M. K. S. (2012). DO Parameter Estimation Program (Version 3.0.3). Retrieved from http://www.seas.ucla.edu/stenstro/DOPar3-0-3.zip

Kottegoda, N. T., \& Rosso, R. (2008). Applied Statistics for Civil and Environmental Engineers (2nd Ed.). Oxford, UK ; Malden, MA: Wiley-Blackwell.

Lee, Y. H., \& Tsao, G. T. (1979). Dissolved oxygen electrodes. In T. K. Ghose, N. Blakebrough, \& A. Fiechter (Eds.), Advances in Biochemical Engineering, Volume 13 (Vol. 13, pp. 35-86). Berlin, Heidelberg: Springer Berlin Heidelberg. Retrieved from http://link.springer.com/10.1007/3540094687_6

Liu, C., Li, S., \& Zhang, F. (2011). The oxygen transfer efficiency and economic cost analysis of aeration system in municipal wastewater treatment plant. Energy Procedia, 5, 2437-2443. http://dx.doi.org/10.1016/j.egypro.2011.03.419

Metcalf \& Eddy (2013). Wastewater Engineering: Treatment and Resource Recovery (5th Ed.). McGraw-Hill Education.

Mueller, J., Boyle, W. C., \& Popel, I. H. J. (2002). Aeration: Principles and Practice, 11(1st Ed.). Boca Raton: CRC Press.

Philichi, T. L., \& Stenstrom, M. K. (1989). Effects of dissolved oxygen probe lag on oxygen transfer parameter estimation. Journal - Water Pollution Control Federation, 61(1), 83-86.

Pittoors, E., Guo, Y., \& Van Hulle, S. W. H. (2014). Oxygen transfer model development based on activated sludge and clean water in diffused aerated cylindrical tanks. Chemical Engineering Journal, 243, 51-59. http://dx.doi.org /10.1016/j.cej.2013.12.069

R Core Team. (2015). R: A Language and Environment for Statistical Computing. Vienna, Austria: R Foundation for Statistical Computing. Retrieved from http://www.R-project.org

Rosso, D., Huo, D. L., \& Stenstrom, M. K. (2006). Effects of interfacial surfactant contamination on bubble gas transfer. Chemical Engineering Science, 61(16), 5500-5514. http://dx.doi.org /10.1016/j.ces.2006.04.018

Rosso, D., Iranpour, R., \& Stenstrom, M. K. (2005). Fifteen Years of Offgas Transfer Efficiency Measurements on Fine-Pore Aerators: Key Role of Sludge Age and Normalized Air Flux. Water Environment Research, 77(3), 266-273. http:// dx.doi.org /10.2175/106143005X41843

Rosso, D., \& Shaw, A. R. (2015). Framework for Energy Neutral Treatment for the 21st Century through Energy Efficient Aeration (Vol. 14). http://dx.doi.org/10.2166/9781780406794

Santos, J. L., \& Farahi, F. (Eds.). (2014). Handbook of Optical Sensors (1st Ed.). Boca Raton, FL: CRC Press. http://dx.doi.org/10.1201/b17641

Schierholz, E. L., Gulliver, J. S., Wilhelms, S. C., \& Henneman, H. E. (2006). Gas transfer from air diffusers. Water Research, 40(5), 1018-1026. http://dx.doi.org /10.1016/j.watres.2005.12.033

Smith, C. A., \& Corripio, A. B. (1997). Principles and Practice of Automatic Process Control (2nd Ed.). New York: Wiley.

Stenstrom, M. K., \& Gilbert, R. G. (1981). Effects of alpha, beta and theta factor upon the design, specification 
and operation of aeration systems. Water Research, 15(6), 643-654. http://dx.doi.org/10.1016/0043-1354(81)90156-1

US EPA. (1989). Design Manual. Fine Pore Aeration Systems (Vol. EPA/625/1-89/023). Retrieved from http://nepis.epa.gov/Exe/ZyPURL.cgi?Dockey=3000464S.txt

Walpole, R. E., Myers, R. H., Myers, S. L., \& Ye, K. E. (2011). Probability and Statistics for Engineers and Scientists (9st Ed.). Boston: Pearson.

YSI Incorporated. (2009). The Dissolved Oxygen Handbook. Retrieved from https://www.ysi.com/parameters/dissolved-oxygen

\section{Copyrights}

Copyright for this article is retained by the author(s), with first publication rights granted to the journal.

This is an open-access article distributed under the terms and conditions of the Creative Commons Attribution license (http://creativecommons.org/licenses/by/3.0/). 